\title{
Polymer- Layered Silicate Nanocomposites for Cryotank Applications
}

\author{
Sandi G. Miller ${ }^{*}$ and Michael A. Meador ${ }^{\dagger}$ \\ Polymeric Materials Branch, NASA Glenn Research Center, Cleveland, OH 44135
}

\begin{abstract}
Previous composite cryotank designs have relied on the use of conventional composite materials to reduce microcracking and permeability. However, revolutionary advances in nanotechnology derived materials may enable the production of ultra-lightweight cryotanks with significantly enhanced durability and damage tolerance, as well as reduced propellant permeability. Layered silicate nanocomposites are especially attractive in cryogenic storage tanks based on results that have been reported for epoxy nanocomposite systems. These materials often exhibit an order of magnitude reduction in gas permeability when compared to the base resin. In addition, polymer-silicate nanocomposites have been shown to yield improved dimensional stability, strength, and toughness. The enhancement in material performance of these systems occurs without property trade-offs which are often observed in conventionally filled polymer composites. Research efforts at NASA Glenn Research Center have led to the development of epoxy-clay nanocomposites with $70 \%$ lower hydrogen permeability than the base epoxy resin. Filament wound carbon fiber reinforced tanks made with this nanocomposite had a five-fold lower helium leak rate than the corresponding tanks made without clay. The pronounced reduction observed with the tank may be due to flow induced alignment of the clay layers during processing. Additionally, the nanocomposites showed CTE reductions of up to $30 \%$, as well as a $100 \%$ increase in toughness.
\end{abstract}

\section{Introduction}

A primary concern in the development of polymer matrix composites for cryogen storage is failure due to matrix microcracking. Under such extreme conditions, increased thermal stresses are the underlying cause of microcracking in polymer composites. As the temperature of the resin deviates from the stress-free temperature, thermal stress in the material increase. These stresses are the result of a difference in the linear coefficient of thermal expansion (CTE) between the fibers and the matrix. When the residual stresses in the material become large enough, they are relieved through physical processes such as delamination and/or microcracking. ${ }^{1}$ Previous work has shown that exposure to cryogenic temperature can be damaging to composite materials, however, cycling composites at these temperatures greatly increases the degree of degradation. Cryogenic cycling can result in significant changes in a composite material, however, shrinkage of the matrix during curing and mismatched coefficients of thermal expansion between the fibers, the matrix, and the ply groups in a laminate are the main causes of the internal stresses that result in laminate microcracking at cryogenic temperatures. ${ }^{1}$

Epoxy resins are commonly investigated and are especially attractive for cryotank applications due to their low cure shrinkage. However, regardless of the curing agent, shrinkage below $\mathrm{T}_{\mathrm{g}}$ increases linearly with a decrease in temperature, so that the operating temperature below $\mathrm{T}_{\mathrm{g}}$ becomes very important. ${ }^{2}$ The magnitude of the resulting internal residual stresses depends on the $\mathrm{T}_{\mathrm{g}}$, CTE, and elastic moduli of the epoxy, as well as the curing conditions and the degree of dimensional constraint. ${ }^{2}$ Therefore, even with a well chosen resin, residual stresses and microcracking remain problematic for the use temperatures of a cryotank.

Research by Timmerman, et al, ${ }^{1}$ has shown that microcracks propagate through an epoxy matrix composite transverse to the fibers in the $\mathrm{x}$-direction, and end at the interface between the plies with different orientations. Modifications have also been made to the matrix, for example, the addition of tougheners to an epoxy resin to lower the extent of matrix microcracking.

*Chemical Engineer, Polymeric Materials Branch, 21000 Brookpark Rd/MS 49-3, Nonmember.

${ }^{\dagger}$ Branch Chief, Polymeric Materials Branch, 21000 Brookpark Rd./M.S. 49-3, Nonmember. 
Microcracking in the central plies provides a pathway for liquid to flow through the laminate and could be disastrous for the storage of cryogenic liquids. This has been well documented in leading to the failure of the X-33 composite fuel tank. In this case, microcracking of the polymer matrix allowed the cryogen to permeate through the inner skin of the tank to the honeycomb core. ${ }^{3}$ In the case of the X-33, microcracking resulted in catastrophic failure of the tank. A variety of methods have been employed to reduce the permeation of cryogen through the composite tank. Both metal and polymer liners have been investigated. ${ }^{4,5}$ The liner does provide an efficient barrier to the cryogen, however there still exists a mismatch in CTE, now between the liner and the composite.

Recently, clay nanocomposites have attracted attention as a viable filler for epoxy composite tanks. The platelet structure of the dispersed clay layers creates an effective barrier to gas permeation. Matrix toughening is achieved through the high specific surface area and aspect ratio of the filler. Layered silicate nanocomposites offer a promising means to overcome many of the issues described above. Numerous reports in the literature describe the benefits to epoxy resin performance when just $2-10 \mathrm{wt} \%$ of an organically modified silicate is dispersed in the resin. $^{6-10}$ Improvements in barrier performance, tensile strength, modulus, $\mathrm{T}_{\mathrm{g}}$, toughness, and decrease in residual stress has been reported. We will focus on the properties that specifically play a role in the development of reliable cryogenic gas storage tanks, often focusing solely on the nanocomposite matrix, rather than the entire composite.

The purpose of this paper is to evaluate the performance of an epoxy-silicate nanocomposite in a cryogenic environment. In the first part of this paper, we investigate Epon 826 epoxy resin as a matrix material for nanocomposite matrix composites. Carbon fiber reinforced test panels and tanks were fabricated and evaluated with respect to permeability and strength. The second half of the paper focuses on methods to improve upon the nanocomposite matrix toughness and dimensional stability.

\section{Experimental}

\section{A. Materials}

Epoxy resin, Epon 826, was generously supplied by Resolution Performance Products. Araldite DY3601, a polypropylene based epoxide, and Jeffamine D230 curing agent were supplied by Huntsman Chemicals. The organically modified clay, Closite 30B was a supplied by Southern Clay Products and the silicate denoted as 'ODA' was prepared by Professor Thomas Pinnavaia's group at Michigan State University. The structures of Epon 826, DY3601, and D230 are shown in Fig. 1.

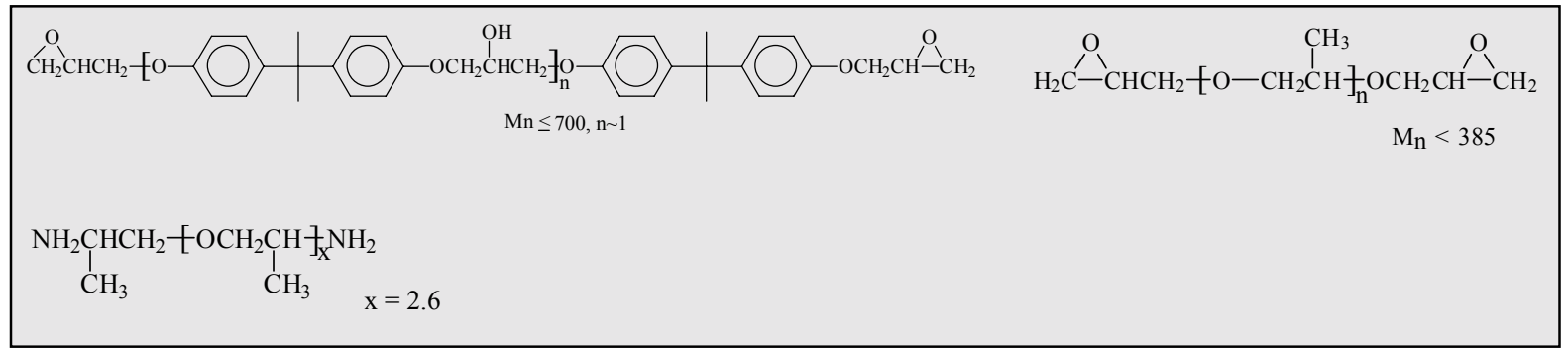

Figure 1. Chemical structure of epoxy resins and curing agent. The structure of Epon 826 epoxy monomer, DY3601 epoxy monomer, and Jeffamine D230 curing agent are illustrated, respectively.

\section{B. Nanocomposite Preparation}

Resin plaques of Epon 826 and DY3601 epoxy blends were prepared in 100:0, 70:30, and 50:50 ratios, based on weight per equivalent epoxide. In each ratio, $25 \mathrm{~g}$ of resin was prepared by combining the appropriate amount of epoxy resin(s) in a jar. Either $2 \mathrm{wt} \%$ or $5 \mathrm{wt} \%$ of organically modified silicate were added and the mixture was stirred with a stir bar for 3 hours at $50^{\circ} \mathrm{C}$. The epoxy/clay mixture was cooled and the D230 curing agent was added. The contents of the jar were poured into a $10.2 \mathrm{~cm}$ by $10.2 \mathrm{~cm}$ mold. The resin was degassed at $50^{\circ} \mathrm{C}$ for 3 hours then cured at $75^{\circ} \mathrm{C}$ for 2 hours and $125^{\circ} \mathrm{C}$ for 2 hours. Plaques with a 50:50 blend of the epoxy resins were prepared following the same procedure, using Epon 826 (13.52g), DY3601 (13.52g), and D230 (6.75g).

\section{Carbon Fiber Reinforced Composite Preparation}

Carbon fiber reinforced composites of Epon 826 were prepared by combining the Epon $826(20 \mathrm{~g})$ and either $2 \mathrm{wt} \%$ or $5 \mathrm{wt} \%$ Closite $30 \mathrm{~B}$ in a jar. The mixture was stirred with a stir bar for 3 hours at $50^{\circ} \mathrm{C}$. The epoxy/clay 
mixture was cooled and the D230 curing agent was added. Prepreg was prepared by brush application of the resinsilicate nanocomposite onto T650-35 carbon fabric, to give a final fiber content of $60 \mathrm{wt} \%$. The prepreg sheets were cut into eight, $10.2 \mathrm{~cm}$ by $10.2 \mathrm{~cm}$, plies and placed in a metal mold. The mold was degassed at $50^{\circ} \mathrm{C}$ for 3 hours, then compression molded at $75^{\circ} \mathrm{C}$ for 2 hours and $125^{\circ} \mathrm{C}$ for 2 hours.

\section{Tank Manufacture}

Neat resin (Epon 826) and nanocomposite matrix (5 wt\% ODA) tanks were prepared by Rocky Mountain Composites, Inc. The 9L tanks, Fig. 2, were prepared by filament winding the carbon fiber through either the neat epoxy or nanocomposite resins. The tanks shown include one neat resin matrix and two with a nanocomposite matrix. The leak rate of helium gas was evaluated at Northrop Grumman over a 24 hour period. The test was performed at room temperature and 25 psi.

\section{E. Characterization}

X-ray diffraction (XRD) patterns were obtained using a Philips XRG 3100 $\mathrm{X}$-ray diffractometer with Ni-filtered $\mathrm{CuK} \alpha$ radiation. The XRD data was recorded

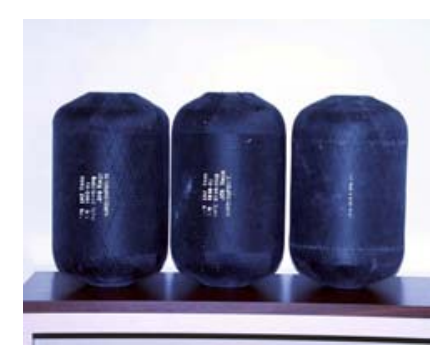

Figure 2. Filament wound resin and nanocomposite matrix tanks.

in the range of $2 \theta=2^{\circ}$ to $32^{\circ}$. Transmission electron microscopy (TEM) samples were prepared by microtoming epoxy nanocomposites, 20 to $70 \mathrm{~nm}$ thick, and floating the sections onto $\mathrm{Cu}$ grids. Micrographs were obtained with a Philips CM 200, using an acceleration voltage of $200 \mathrm{kV}$. CTE was characterized using a TMA 2940 Thermomechanical analyzer. The tests were run at a ramp rate of $5{ }^{\circ} \mathrm{C} / \mathrm{min}$ using a $2 \mathrm{~g}$ load. Tensile tests were run on an Instron 4505 using the Series IX data acquisition software. The tests were run according to ASTM D638.

\section{Results and Discussion}

\section{A. Nanocomposites for Carbon Fiber Reinforced (CFR) Composite}

Epon 826 was chosen as the matrix resin for tank manufacture because it is readily available, is amenable to nanoparticulate blending and filament winding, and has been extensively utilized as a matrix resin for layered silicate clay nanocomposites. The layered clay material was Closite $30 \mathrm{~B}$ which has also been widely investigated in layered silicate nanocomposites. The dispersion of Closite 30B in Epon 826, by the technique used in this paper, may be described as a combination of intercalated and exfoliated nanocomposite morphologies. This was confirmed by both XRD and TEM.

As described previously, the properties of interest for the polymer composite cryotank include: resin permeability, CTE, and composite strength. The nanocomposite permeability and CTE were evaluated prior to CFR composite preparation. The CTE was measured at a temperature below the resin $\mathrm{T}_{\mathrm{g}}$. Figure 3 plots the reduction of CTE resulting from the nanocomposite structure. A reduction of up to $25 \%$ was observed.

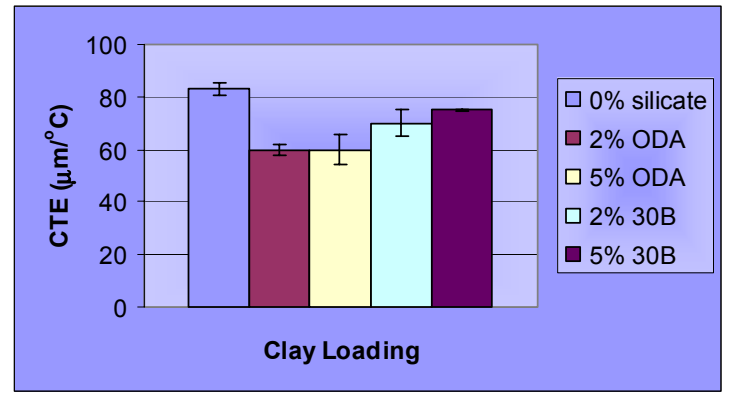

Figure 3. CTE measurements of neat resin and nanocomposites

The dimensional stability of a resin is commonly improved by dispersion of the rigid nanoparticles. The large surface area of the silicate inhibits the motion of the epoxy when the resin is exposed to temperature changes. The result is a reduction in CTE. ${ }^{11}$ 
The helium permeability of the materials was measured, as this best mimics that of hydrogen. Measurements were taken before and after cycling, and are reported in Fig. 4. Prior to cycling, the helium permeability of the neat resin was an order of magnitude greater than that of the nanocomposite. The barrier performance improved with increased clay loading. After cycling, the significant reduction in permeability was retained with the nanocomposite structure.

(a)
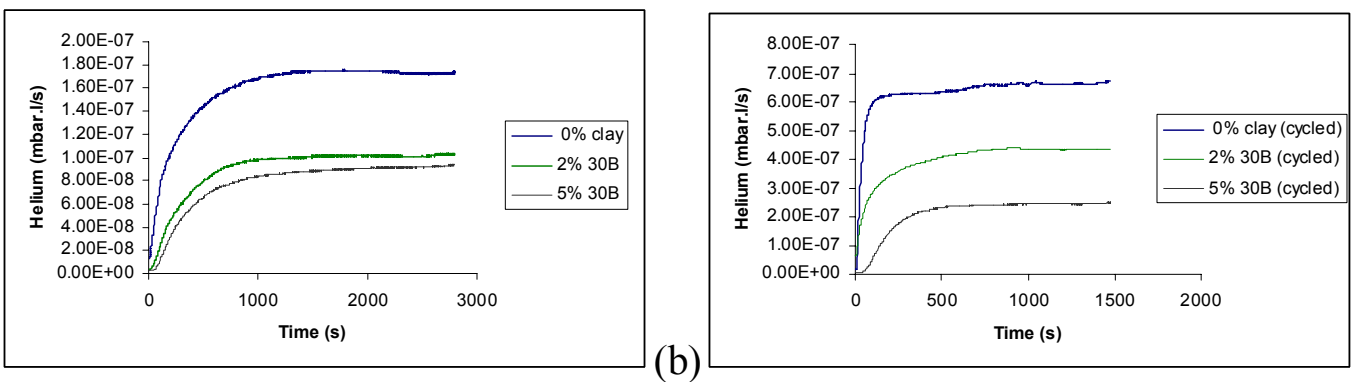

(c)

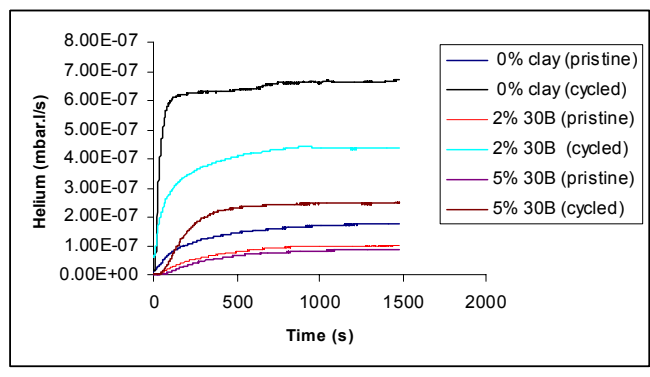

Figure 4. Helium permeability measurements. The permeability of resins are shown (a) before cycling and (b) after cycling. Plot (c) illustrates a comparison of the data.

When comparing the permeability results before and after cycling, Fig. 4c, we observed a large increase in the permeability of the neat resin, from $1.7 \mathrm{E}-7$ (pristine) to $6.5 \mathrm{E}-7$ (cycled). The permeability of the $2 \% 30 \mathrm{~B}$ sample is also increased, to a lesser extent; approximately 1.0E-7 (pristine) to 4.0E-7 (cycled). Further increasing the clay loading to $5 \mathrm{wt} \%$ offers better resistance to thermal cycling. The permeability increases from approximately $8.8 \mathrm{E}-8$ to $2.4 \mathrm{E}-7$. Furthermore, the permeability of the cycled nanocomposite $(5 \mathrm{wt} \% 30 \mathrm{~B})$ is not much higher than the permeability of the pristine $0 \%$ clay sample. The ODA nanocomposite sample exhibited similar results. The mechanism of nanocomposite permeability reduction has been reported in the literature as the clay layers increasing the path length that a permeant must travel to diffuse through a component. As a result, the permeation over a given length of time is decreased.

There was no evidence of microcracking observed in the samples after cycling. The nanocomposite compositions evaluated consisted solely of the epoxy matrix and the silicate nanoparticles. In such a case, microcracking would not be expected because it is the CTE mismatch with carbon fiber reinforcement which leads to stress build up. The greater change in the neat resin permeability is likely due to differences in free volume following cryogenic cycling. On cycling, the sample is heated above $\mathrm{T}_{\mathrm{g}}$; increasing the free volume. The resin is then quickly cooled, locking that structure in place. However, the movement of the epoxy chains in the nanocomposite are inhibited due to the large surface area and rigid nature of the layered silicates. Therefore, the free volume will increase to a lesser extent on heating. ${ }^{12}$ This behavior was observed in the CTE measurements, and is extended to changes in the $\mathrm{T}_{\mathrm{g}}$ after cycling. Material glass transition temperatures are listed in Table $1 .{ }^{12}$

Table 1. Glass transition temperature before and after cryogenic cycling.

\begin{tabular}{|c|c|c|}
\hline Sample & $\mathbf{T}_{\mathbf{g}}$ - Before Cycling & $\mathbf{T}_{\mathbf{g}}$ - After Cycling \\
\hline $0 \mathrm{wt} \%$ clay & 65 & 83 \\
\hline $2 \mathrm{wt} \%$ ODA & 77 & 80 \\
\hline $5 \mathrm{wt} \%$ ODA & 71 & 79 \\
\hline $2 \mathrm{wt} \%$ 30B & 77 & 81 \\
\hline $5 \mathrm{wt} \%$ 30B & 77 & 81 \\
\hline
\end{tabular}


The smaller change in Tg after cycling implies less change in the free volume of the epoxy matrix resulting from the repeated temperature change.

The Epon 826 epoxy resin and nanocomposites were used as matrix resins to prepare carbon fiber reinforced composites. The flexural strength of the samples were examined before and after just ten cycles of 20 minutes in liquid nitrogen, and 20 minutes at room temperature. The addition of clay reduced the flexural strength of the composite, Fig. 5. Similar reductions in flexural strength and toughness have been observed with brittle matrices. However, the nanocomposites retained their strength after cycling to a much greater extent than the pristine epoxy matrix composites. The retention of physical strength and barrier performance are essential considerations for a polymer matrix tank.

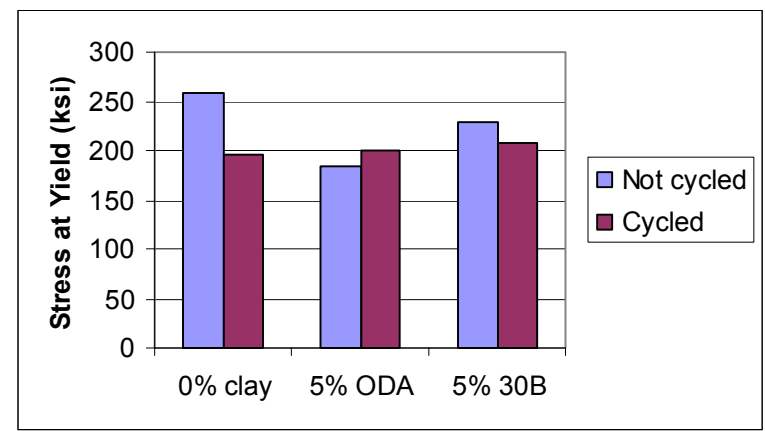

Figure 5. Flexural strength of composites before and after cycling.

Finally, epoxy and epoxy- clay matrix tanks were manufactured by Rocky Mountain Composites, Inc., in collaboration with Northrop Grumman and Michigan State University. The leak rate was investigated by Northrop Grumman and the nanocomposite tanks showed a significant reduction in helium leak rate over a 24 hour period. The tank leak rate reduction and the permeability data on resin cycling both offered promising results. The toughness of the resin however, and the CTE, are important parameters that are not readily obtainable simply by exfoliating the silicate. These properties, especially toughness, tend to depend on the nature of the matrix resin. This is investigated further in the remainder of this paper.

\section{B. Nanocomposites from Epoxy Blends}

The resin glass transition temperature is an important parameter with respect to the manner in which the layered silicate clay provides reinforcement. The $\mathrm{T}_{\mathrm{g}}$ is dependent on the matrix resin, the organic modifier on the clay, and cryogenic cycling. The $\mathrm{T}_{\mathrm{g}}$ of the Epon 826 resin used previously may be modified by the introduction of a second, low $\mathrm{T}_{\mathrm{g}}$ epoxy monomer. Therefore, samples were prepared where the ratio of Epon 826 to DY3601 epoxy components was varied, such that a 70:30 ratio resin/nanocomposite was glassy at room temperature ( $\mathrm{T}_{\mathrm{g}}=25$ to $31^{\circ} \mathrm{C}$ ), and 50:50 ratio resins/nanocomposites were rubbery $\left(\mathrm{T}_{\mathrm{g}}=-1\right.$ to $\left.-5^{\circ} \mathrm{C}\right)$. The material $\mathrm{T}_{\mathrm{g}}$ had little effect on dispersion, however it played a very large role in the measured toughness of the sample.

The silicate dispersion was characterized by XRD and TEM, Fig. 6. The XRD data showed little to no diffraction peak corresponding to the silicate $\mathrm{d}_{001}$ interplanar spacing. The results implied the silicate was well separated from the starting aggregated state. The exception was 70:30/5\% ODA, where the ODA $\mathrm{d}_{001}$ diffraction peak shifted from $2 \theta=4.10\left(\mathrm{~d}_{001}=2.1 \mathrm{~nm}\right)$ to a lower $2 \theta=2.5^{\circ}\left(\mathrm{d}_{001}=3.5 \mathrm{~nm}\right)$. This indicates an intercalated morphology.
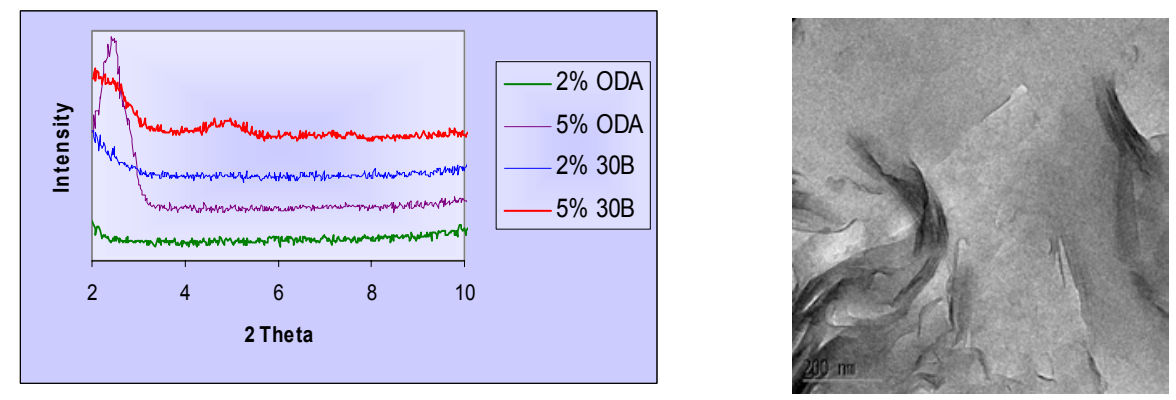

Figure 6: XRD of nanocomposites in a 70:30 epoxy ratio. TEM image of $5 \mathrm{wt} \%$ Closite 30B clay, dispersed in 70:30 epoxy resin. 
The TEM images show regions containing several stacked clay layers, indicating that the nanocomposite morphology was a combination of intercalated and exfoliated clay. Dispersion of the nanoparticle is critical because it is the large interface of the individual silicate sheets which allow some of the nanocomposite properties, such as increased $\mathrm{T}_{\mathrm{g}}$, decreased permeability, reduced CTE, and improved strength and toughness.

Pinnavaia et $\mathrm{l}^{13-15}$ have noted that flexible resin systems with low $\mathrm{T}_{\mathrm{g}}$ show a much higher increase in modulus and tensile strength with the addition of an organoclay, than do rigid systems. Giannelis et $a l^{16,17}$ provided experimental evidence that a nanocomposite under tensile stress, at a temperature much higher than $\mathrm{T}_{\mathrm{g}}$, allows nanoparticle alignment in the direction of the stress, thereby providing a mechanism for energy dissipation.

Figure 7 plots the toughness values of the silicate-epoxy nanocomposites as given by the energy required to break the tensile specimens. This value is calculated by the area under the load displacement curve following tensile tests. The load displacement curve approximates a stress-strain curve, as the stress and strain values may be calculated from load displacement data.
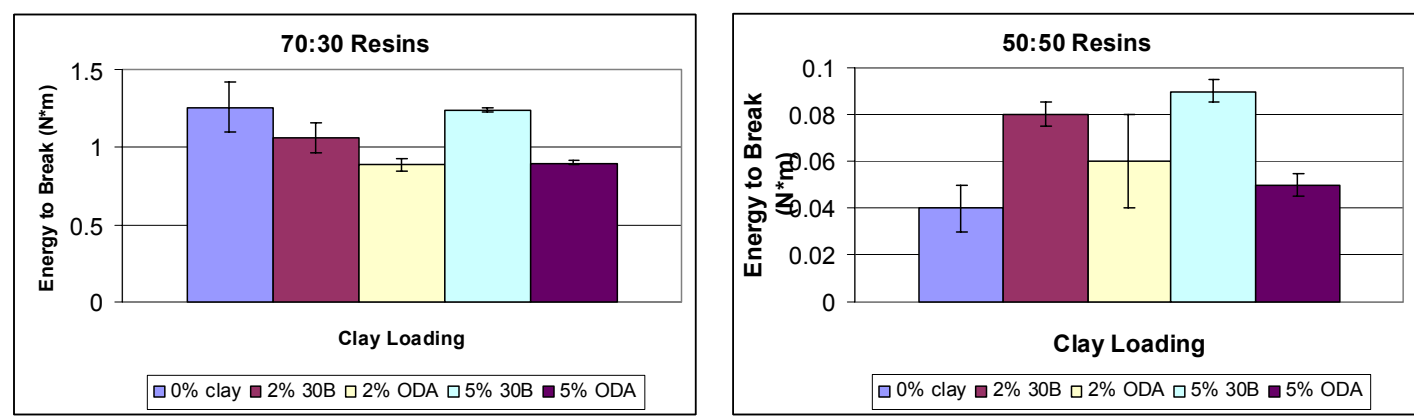

Figure 7. Tensile test results of nanocomposite prepared with 70:30 and 50:50 ratio epoxy matrices.

It should be noted that the 50:50 samples are rubbery at RT, therefore the ends of the dogbones suffered some crushing in the grips for tensile testing. The tensile data shows a decreased toughness with the 70:30 nanocomposites compared to the neat resin, whereas the 50:50 nanocomposites increase resin toughness by more than $100 \%$. Although the test conditions and chemical structure of the blends are the same, it is clear that a rubbery blend exhibits improved toughness on dispersion of the layered silicate. While the strength of this resin is insufficient for structural applications, the mobility of the silicate has proven to be important from a toughening aspect and optimizing that mobility may dictate the materials selection for nanocomposites with both strength and toughness.

CTE is also a critical concern for resins to be used in composite applications, and necessary to mitigate microcracking in cryogen tanks. The addition of nanoclay to the epoxy resin has been shown to reduce the resin $\mathrm{CTE}$ and may therefore reduce the mismatch in thermal expansion between resin and a composite reinforcement (for example, carbon fiber). Figure 8 compares the CTE values of the neat resins and corresponding nanocomposites at temperatures below $\mathrm{T}_{\mathrm{g}}$, which is the primary temperature range of this application.

A reduction in CTE was observed in most cases because addition of the rigid clay nanoparticle inhibits polymer chain motion. By inhibiting chain motion, the dimensional stability of the resin is improved. Up to $30 \%$ reductions in CTE were observed with the 70:30 epoxy nanocomposites. However, the nanocomposite structure had no effect, or increased, the CTE of the 50:50 resin. Additionally, the CTE of the 50:50 resins was lower than that of the 70:30. Both results were unexpected. It was thought that the higher aliphatic content, and the greater flexibility of the 50:50 resin would result in a higher CTE. Additionally it was believed that the rigid clay would be more effective in reducing the CTE of the more flexible 50:50 resin. It is unclear why the silicate dispersion did not affect the CTE in the 50:50 resin.

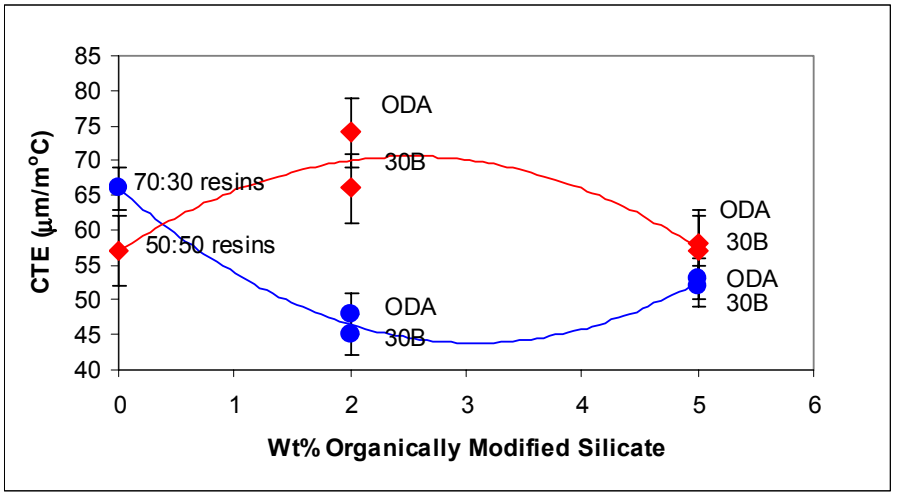

Figure 8. CTE values of neat resins and nanocomposites. 
The oxygen permeability of some nanocomposite samples was within experimental error of the measured neat resin permeability, while other nanocomposite samples actually displayed an increased permeability. This was unexpected as well, given the large reductions in permeability with the nanocomposites of $100 \%$ Epon 826 matrix. The data is listed in Table 2.

Table 2. Oxygen permeability of neat resin and nanocomposites.

\begin{tabular}{|c|c|c|}
\hline Sample & Permeability (50:50) & Permeability (70:30) \\
\hline $0 \%$ clay & $1341.61^{+} /-57.28$ & $206.84^{+} /-25.12$ \\
\hline $2 \% 30 \mathrm{~B}$ & $1345.36^{+} /-72.98$ & $205.37^{+} /-20.06$ \\
\hline $5 \% 30 \mathrm{~B}$ & $1347.55^{+} /-61.60$ & $240.84^{+} /-8.42$ \\
\hline $2 \%$ ODA & $1462.03^{+} /-82.40$ & $210.64^{+} /-4.71$ \\
\hline $5 \%$ ODA & $1553.22^{+} /-36.54$ & $280.78^{+} /-5.17$ \\
\hline
\end{tabular}

The larger permeability of the 50:50 samples is reasonable due to the greater alkyl content and higher chain mobility of these resins. A possible explanation for the permeability result is that the clay may reside in closer contact to the aromatic component of the blend. The permeability of the sample is dictated by the aliphatic portion, therefore an abundance of clay in the aromatic portion would yield little change in barrier properties of the blend. This postulation is supported by SEM images of the nanocomposites, which exhibit regions rich in layered silicate and regions void of silicate, as seen in Figure 9. While this suggests phase separation of the epoxy blend, DSC thermograms showed only one $\mathrm{T}_{\mathrm{g}}$. Therefore, the idea of full phase separation is not supported.

However, literature data ${ }^{18}$ and preliminary evidence does suggest an affinity of the silicate for the aromatic segments over the aliphatic. The interaction between the silicate clay and an aromatic or aliphatic compound was empirically evaluated by the addition of $0.5 \mathrm{~g}$ Closite $30 \mathrm{~B}$ in $20 \mathrm{~mL}$ of either benzene or heptane. On addition to heptane, the clay remained in powder form and immediately precipitated to the bottom of the

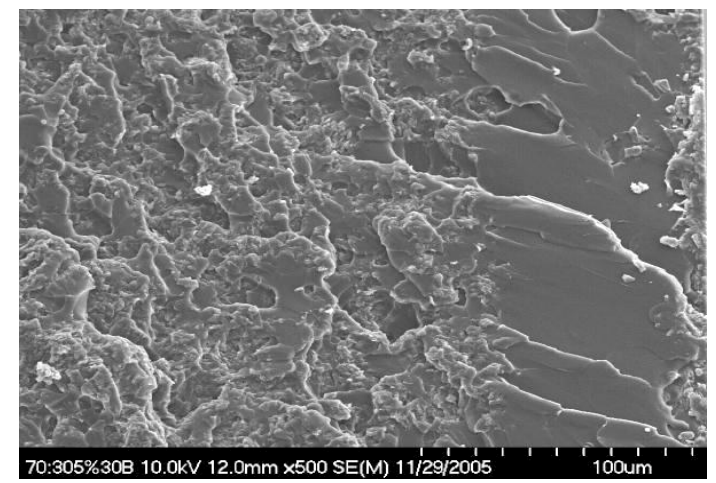

Figure 9. SEM image $5 \mathrm{wt} \%$ Closite 30B dispersed in a 70:30 epoxy ratio blend. solution. Mixing Closite 30B with benzene resulted in the clay instantly swelling and dispersing throughout the solvent. The swelling indicated a much greater attraction between the aromatic compound and the silicate clay. A more comprehensive study was reported in the literature ${ }^{19}$ where the ability of a hexadecyl-functionalized synthetic clays to disperse and form gels in organic solvents was investigated. It was found that at $5-10 \mathrm{wt} \%$, the organically modified clays formed gels in selected aromatic solvents. The gels of all clays used in the study were stronger in toluene than in a branched alkyl solvent. The conclusion was that the synthetic clays are potentially more suited to be dispersed into polystyrene, which is structurally more similar to aromatic solvents, than in polymers structurally similar to the alkyl solvent, such as polypropylene. Further investigation is necessary to determine if such an affect played a role in the permeability results measured for these systems.

\section{Conclusions}

The nanocomposites analyzed following cryogenic cycling demonstrated an ability to retain strength and barrier characteristics better than the corresponding neat resin. Furthermore, the results indicate that the addition of a layered silicate clay to an appropriate matrix can significantly improve the performance of a polymer matrix composite for cryotank applications. While the dispersion of the silicate may not simultaneously yield all the desired property enhancements, tailoring the resin system will allow optimization of a tank design. 


\section{Acknowledgments}

The authors would like to acknowledge NASA support under the Advanced Technology Development Program under the Exploration Mission Systems Division for funding. We would also like to Dr. Edward Silverman at Northrop Grumman for collaboration in the composite tank development and characterization, Dr. Thomas J. Pinnavaia for providing the oxygen permeability measurements and the organically modified silicate, and Ms. Sofia Vilarino, Dr. Jianren Zhou, and Dr. David Hui at Prairie View A\&M and The University of New Orleáns for the cryocycling experiments and Helium permeability measurements.

\section{References}

1. Timmerman, J.F., Hayes, B.S., and Seferis, J.C., "Nanoclay reinforcement effects on the cryogenic microcracking of carbon fiber/epoxy composites," Composites Science and Technology 2002;62:12491258.

2. Akelah, A., and Moet, A., "Polymer-clay nanocomposites: Free-radical grafting of polystyrene on to organophilic montmorillonite interlayers," Journal or Materials Science 1996;31:3589-3596.

3. NASA, Final Report of the X-33 Liquid Hydrogen Tank Test Investigation Team, George C. Marshall Space Flight Center, Huntsville, NASA Report, 2000, May.

4. Bechel, V.T., Kim, R.Y., and Donaldson, S.L., "Composites containing barrier layers for reduced permeability at cryogenic temperatures," Proceedings of the $47^{\text {th }}$ AIAA/ASME/ASCE/AHS/ASC SDM Conference, AIAA 2006-2092, Newport, RI, May, 2006.

5. Mallick, K., Cronin, J., Arzberger, S., and Tupper, M.L., "Ultralight linerless composite tanks for in-space applications," Proceedings of the Space 2004 Conference and Exhibit, AIAA 2004-5801, San Diego, CA, September, 2004.

6. Kojima, Y., Usuki, A, Kawasumi, M., Okada, A., Fukushima, Y., Kurauchi, T., and Kamigaito, O., "Mechanical properties of nylon 6-clay hybrid," Journal of Materials Research 1992;8(5):1185-1189.

7. Wu, J., and Lerner, M.M., "Structural, thermal, and electrical characterization of layered nanocomposites derived from Na-montmorillonite and polyethers," Chemistry of Materials 1993;5:835-838.

8. Shelley, J.S., Mather, P.T., and DeVries, K.L., "Reinforcement and environmental degradation of nylon6/clay nanocomposites," Polymer 2001;42:5849-5858.

9. Brown, J.M., Curliss, D., and Vaia, R.A., "Thermoset-layered silicate nanocomposites. Quaternary ammonium montmorillonite with primary diamine cured epoxies," Chemistry of Materials 2000;12:33763384.

10. Tyan, H.L., Leu, C.M., and Wei, K.H., "Effect of reactivity of organics-modified montmorillonite on the thermal and mechanical properties of montmorillonite/polyimide nanocomposites," Chemistry of Materials 2001;13:222-226.

11. Yasmin, A., Luo, J.J., Abot, J.L., and Daniel, I.M., "Mechanical and thermal behavior of clay/epoxy nanocomposites," Composites and Science Technology 2006;66:2415-2422.

12. Martinez-Vilarino, S., Miller, S.G., Zhou, J., Naya, S., Artiaga, R., and Hui, D., "Thermal characterization of layered silicate nanocomposites subjected to thermal cycling," Submitted for publication

13. Becker, O., Varley, R., and Simon, G., "Morphology, thermal relaxations and mechanical properties of layered silicate nanocomposites based upon high-functionality epoxy resins," Polymer 2002;43(16):43654373.

14. Wang, M.S., and Pinnavaia, T.J., "Clay-polymer nanocomposites formed from acidic derivatives of montmorillonite and an epoxy resin," Chemistry of Materials 1994;6(4):468-474.

15. Lan, T., and Pinnavaia, T.J., "Clay-reinforced epoxy nanocomposites," Chemistry of Materials 1994;6(12):2216-2219.

16. Shah, D., Maiti, P., Jiang, D.D., Batt, C.A., and Giannelis, E.P., "Effect of nanoparticle mobility on toughness of polymer nanocomposites," Advanced Materials 2005;17(5):525-528.

17. Shah, D., Maiti, P., Gunn, E., Schmidt, D.F., Jiang, D.D., Batt, C.A., and Giannelis, E.P., "Dramatic enhancements in toughness of polyvinylidene fluoride nanocomposites via nanoclay-directed crystal structure and morphology," Advanced Materials 2004;16(14):1173-1177.

18. Campbell, S.G., and Scheiman, D., "Orientation of aromatic ion exchange diamines and the effect on melt viscosity and thermal stability of PMR-15/silicate nanocomposites," High Performance Polymers 2002;3(14):17-30. 
19. Chastek, T.T., Stein, A., and Macosko, C., "Hexadecyl-functionalized lamellar mesostructured silicates and aluminosilicates designed for polymer-clay nanocomposites. Part II: Dispersion in organic solvents and in polystyrene," Polymer 2005;46(12):4431-4439. 